\title{
Effect of 2, 6-Dichlorobenzonitrile on Amoebicidal Activity of Multipurpose Contact Lens Disinfecting Solutions
}

\author{
Eun-Kyung Moon ${ }^{1}$, Seungeun Lee ${ }^{2}$, Fu-Shi Quan ${ }^{1,3}$, Hyun-Hee Kong ${ }^{2, *}$ \\ 'Department of Medical Zoology, Kyung Hee University School of Medicine, Seoul 02447, Korea; '2Department of Parasitology, Dong-A University \\ College of Medicine, Busan 49201, Korea; ${ }^{3}$ Biomedical Science Institute, Kyung Hee University, Seoul 02447, Korea
}

\begin{abstract}
Multipurpose contact lens disinfecting solutions (MPDS) are widely used to cleanse and disinfect microorganisms. However, disinfection efficacy of these MPDS against Acanthamoeba cyst remain insufficient. 2, 6-dichlorobenzonitrile (DCB), a cellulose synthesis inhibitor, is capable of increasing the amoebical effect against Acanthamoeba by inhibiting its encystation. In this study, we investigated the possibility of DCB as a disinfecting agent to improve the amoebicidal activity of MPDS against Acanthamoeba cyst. Eight commercial MPDS (from a to h) were assessed, all of which displayed insufficient amoebicidal activity against the mature cysts. Solution e, f, and h showed strong amoebicidal effect on the immature cysts. Amoebicidal efficacy against mature cysts remained inadequate even when the 8 MPDS were combined with $100 \mu \mathrm{M}$ DCB. However, 4 kinds of MPDS (solution d, e, f, and h) including $100 \mu \mathrm{M}$ DCB demonstrated strong amoebicidal activity against the immature cysts. The amoebicidal activity of solution $d$ was increased by addition of DCB. Cytotoxicity was absent in human corneal epithelial cells treated with either DCB or mixture of DCB with MPDS. These results suggested that DCB can enhance the amoebicical activity of MPDS against Acanthamoeba immature cyst in vitro.
\end{abstract}

Key words: Acanthamoeba, amoebicidal effect, MPDS, DCB, cytotoxicity

Acanthamoeba keratitis associated with contact lenses wearers has been increasing in recent years [1,2]. For cleansing, rinsing, storing, and disinfecting microorganisms, multipurpose contact lens disinfecting solutions (MPDS) are widely used. However, the majority of MPDS retailed in Korea are ineffective against Acanthamoeba, especially the cyst [3]. Acanthamoeba trophozoites can convert itself into highly resistant cyst form, which diminishes the effectiveness of available therapeutic agents [4]. For this reason, new and more efficacious treatment options against cysts have been proposed and are still being examined [5-8].

Cellulose is the main component of the cyst wall [9]. Cellulose synthesis inhibitor 2, 6-dichlorobenzonitrile (DCB) blocked the encystment of Acanthamoeba and improved the anti-amoebic effects $[7,10]$. In this study, we tested whether DCB can enhance the amoebicidal effects of the MPDS against Acanthamoeba, especially the cysts.

- Received 18 July 2018, revised 2 October 2018, accepted 10 October 2018.

*Corresponding author (hhkong@dau.ac.kr)

(c) 2018, Korean Society for Parasitology and Tropical Medicine

This is an Open Access article distributed under the terms of the Creative Commons Attribution Non-Commercial License (http://creativecommons.org/licenses/by-nc/4.0) which permits unrestricted non-commercial use, distribution, and reproduction in any

medium, provided the original work is properly cited.
Acanthamoeba castellanii Castellani was obtained from the American Type Culture Collection (ATCC 30011), and axenically cultured in PYG (Protose peptone-Yeast extract-Glucose) medium. Encystation of Acanthamoeba was performed in encystment media [11]. DCB was purchased from Sigma Aldrich. Eight types of MPDS (Table 1) were used to determine amoebicidal activities against Acanthamoeba cyst by the most probable number (MPN) technique [12].

Almost all MPDS showed insufficient amoebicidal activity against the 72 hr-induced mature cysts (Fig. 1A). Even though $100 \mu \mathrm{M}$ DCB was added to the 8 MPDS, no significant differences were found between MPDS alone and MPDS combined with DCB against the mature cysts (Fig. 1B). The amoebicidal activities of the MPDS with or without DCB were insufficient against the 48 hr-induced cyst (Supplementary Fig. S1). Three of the 8 MPDS (solution e, f, and h) showed sufficient amoebicidal activities against $24 \mathrm{hr}$-induced immature cysts (Fig. 2A). Combining $100 \mu \mathrm{M}$ DCB to the 8 commercial MPDS, 4 (solution $d, e, f$, and h) out of 8 MPDS showed sufficient amoebicidal activities against the immature cysts (Fig. 2B). The amoebicidal activity of MPDS-d was increased against immature cysts upon addition of DCB. MPDS-a combined with DCB displayed slightly increased amoebicidal activity against 
Table 1. Ingredients of MPDS tested in this study

\begin{tabular}{|c|c|c|c|c|c|c|}
\hline MPDS & Manufacturer & Preservative & Buffer system & $\begin{array}{l}\text { Cleaning or } \\
\text { lubricating agent }\end{array}$ & Chelating agent & etc. \\
\hline a & $\mathrm{H}$. & $\mathrm{PHMB}$ & - & - & - & $\mathrm{NaCl}$ \\
\hline b & C. & PHMB & - & - & - & - \\
\hline c & P. & $20 \% \mathrm{PHMB}$ & $\begin{array}{l}\text { Sodium borate, } \\
\text { Boric acid }\end{array}$ & Ploxamine 1107 & $\begin{array}{l}\text { EDTA-2Na, } \\
\text { Sodium chloride }\end{array}$ & $\begin{array}{l}\text { 30\% etidronic acid tetrasodium, } \\
\text { Hydroxypropyl Methylcellulose }\end{array}$ \\
\hline$d$ & B. & $20 \%$ PHMB & - & - & - & $\begin{array}{l}\text { Polyquaternium-1(35\%w/w), } \\
\text { Sodium Hyaluronate, Sulfobetaine3-10 }\end{array}$ \\
\hline e & B. & $20 \%$ PHMB & - & - & - & Etidronic acid tetrasodium 30\% \\
\hline$f$ & B. & PHMB & - & - & - & 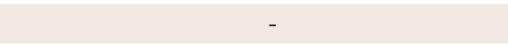 \\
\hline g & A. & $-{ }^{*}$ & - & - & - & $\begin{array}{l}\text { N3-[(dimethylamino)propyl]tetradecanamide, } \\
\text { Poly quatermium-130\%, } \\
\text { EDTA-2Na }\end{array}$ \\
\hline h & A. & - & - & - & - & $\begin{array}{l}\text { Polyquatermium-1(polyquad), } \\
\text { N-[3-(dimethyl amino)propyl], } \\
\text { Tetradecanamide (AL-6289), } \\
\text { Myristamidopropildemethylamine }\end{array}$ \\
\hline
\end{tabular}

PHMB, polyhexamethylene biguanide.

*not mentioned in manufactures.
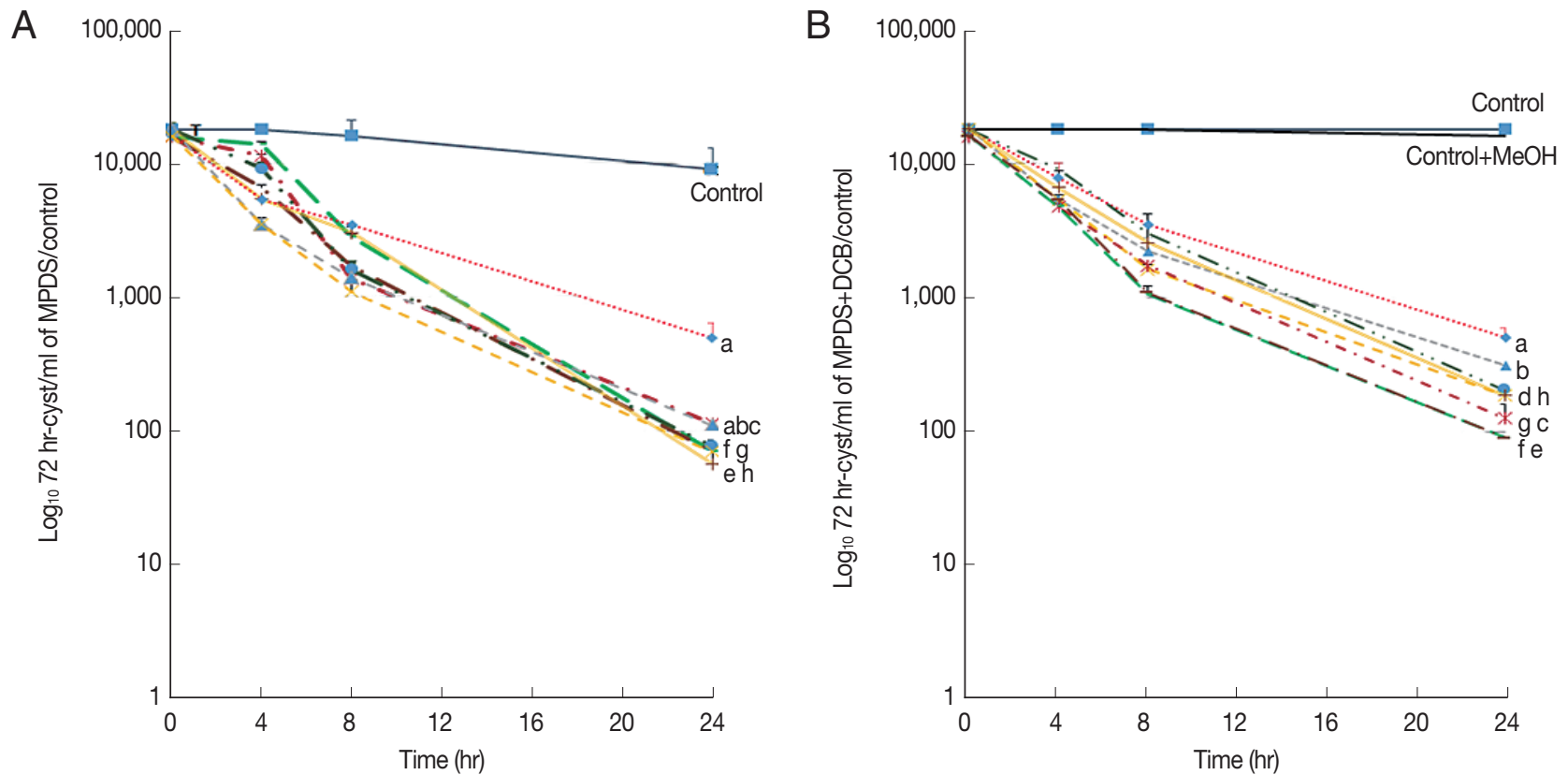

Fig. 1. A most probable number of Acanthamoeba 72 hr-induced cysts after incubation with 8 different types of MPDS (solution a-h) and the combination of MPDS with $100 \mu \mathrm{M}$ DCB. (A) illustrates amoebicidal activity of MPDS against 72 hr-induced cysts, and (B) showed that of MPDS combined with $100 \mu \mathrm{M}$ DCB. Data are presented as mean \pm SEM from 3 independent experiments.

the immature cyst (Fig. 2B). Encystation ratio revealed 0\% mature cysts at $0 \mathrm{hr}$ induction, $27 \%$ mature cysts at $24 \mathrm{hr}$ induction, 55\% mature cysts at $48 \mathrm{hr}$ induction, and $84 \%$ mature cysts at $72 \mathrm{hr}$ induction when incubated in encystation media [13]. We supposed that mature cyst, immature cyst (encysting cyst) and trophozoite were mixed in $24 \mathrm{hr}$-induced group (Fig. 2 ), and the DCB acted on immature cyst by blocking its encys- tation, thereby enhancing the amoebicidal effect on the immature cyst.

To determine the cytotoxicity of DCB, human corneal epithelial (HCE) cells were treated with $100 \mu \mathrm{M}$ DCB and 8 kinds of MPDS combined with DCB. Cytotoxicity was assessed visually after Giemsa staining and optical density measurement at $590 \mathrm{~nm}$ after $0.1 \mathrm{ml}$ of cells were solubilized in 5\% sodium 

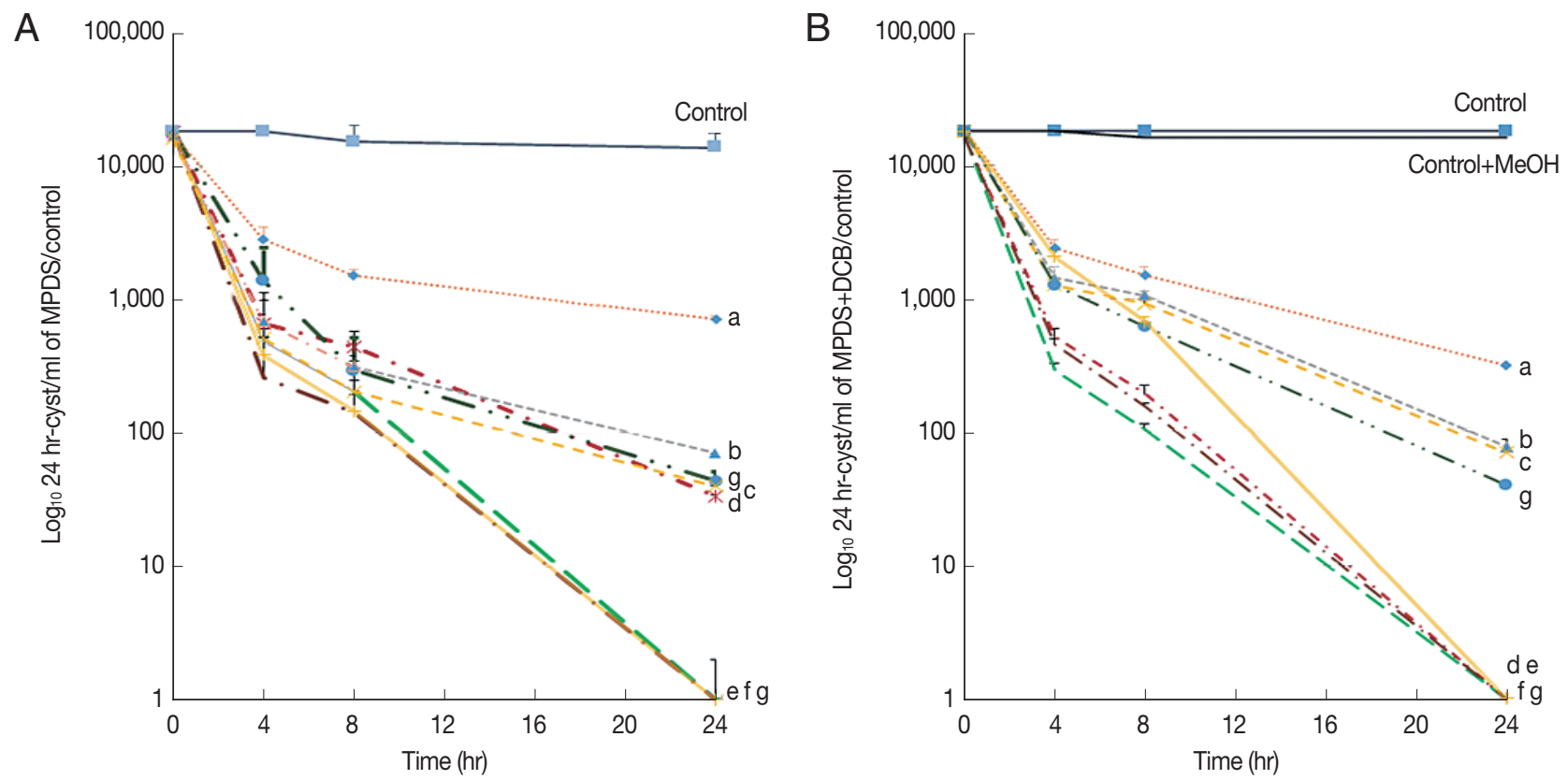

Fig. 2. A most probable number of Acanthamoeba 24 hr-induced cysts after incubation with 8 commercial MPDS (solution a-h) and the combination of MPDS with $100 \mu \mathrm{M}$ DCB. (A) showed amoebicidal activity of MPDS to $24 \mathrm{hr}$-induced cysts. (B) showed that of MPDS combined with $100 \mu \mathrm{M}$ DCB. Data are presented as mean \pm SEM from 3 independent experiments.

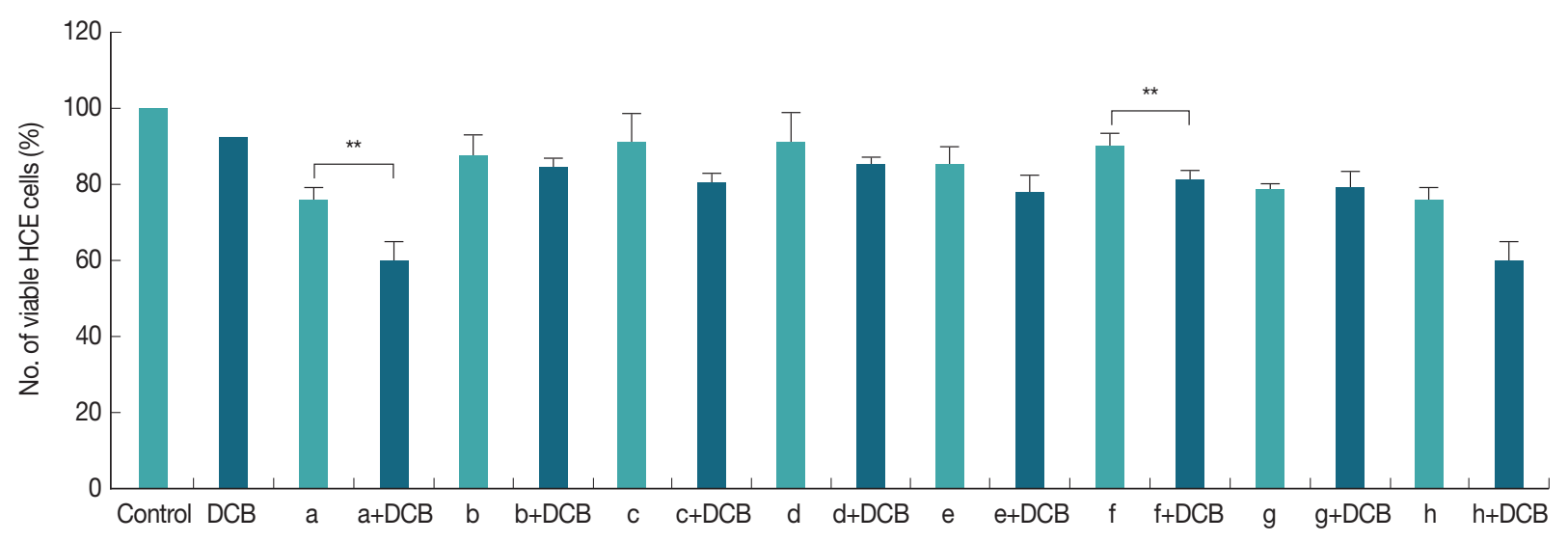

Fig. 3. Cytotoxicity of $100 \mu \mathrm{M} D C B$ and MPDS combined with DCB on human corneal epithelial (HCE) cells. HCE cells were unaffected by incubation with $100 \mu \mathrm{M}$ DCB for $30 \mathrm{~min}$. Most MPDS with DCB showed no apparent cytotoxicity against HCE cells, except for the combinations of DCB with MPDS-a and f. Data are presented as mean \pm SEM from 3 independent experiments. ${ }^{*}$ The means are significantly different at $P<0.01$ by student $t$-test.

dodecyl sulfate. Percent cytotoxicity was calculated according to the following formula: \% cytotoxicity $=100-[(\mathrm{OD}$ of the experimental well-OD of HCE cell alone)/OD of control cells] $\times$ 100. Compared to the control solution, $100 \mu \mathrm{M}$ DCB did not cause cytotoxicity to HCE cells after 30 min of incubation (Fig. 3). Most MPDS combined with DCB showed no significant cytotoxicity towards HCE cells (Fig. 3). Minor levels of cytotoxicity was detected in HCE cells treated with MPDS-a and MPDS-f combined with DCB.
As detailed composition of the MPDS are confidential, it is difficult to explain the mechanism that triggered the enhanced cytotoxicity upon addition of DCB. Despite the presence of cytotoxicity, it can be assumed that DCB will be diluted with tears within minutes, thereby reducing its concentration and ultimately its cytotoxicity. Furthermore, it is unlikely that cellulose biosynthesis inhibitor such as DCB will have significant effect on human cells, which lack cellulose synthesis mechanism. Our results suggested the possibility of DCB as a disin- 
fecting agent to improve the amoebicidal activity of MPDS against Acanthamoeba immature cyst. This may be helpful in the prevention of Acanthamoeba infection associated with contact lens usage.

\section{ACKNOWLEDGMENT}

This work was supported by the National Research Foundation of Korea (NRF) grant funded by the Ministry of Education (No. 2015R1D1A1A01057265).

\section{CONFLICT OF INTEREST}

These authors have no conflict of interest related with this study.

\section{REFERENCES}

1. Joslin CE, Tu EY, Shoff ME, Booton GC, Fuerst PA, McMahon TT, Anderson RJ, Dworkin MS, Sugar J, Davis FG, Stayner LT. The association of contact lens solution use and Acanthamoeba keratitis. Am J Ophthalmol 2007; 144: 169-180.

2. Verani JR, Lorick SA, Yoder JS, Beach MJ, Braden CR, Roberts JM, Conover CS, Chen S, McConnell KA, Chang DC, Park BJ, Jones DB, Visvesvara GS, Roy SL. National outbreak of Acanthamoeba keratitis associated with use of a contact lens solution, United States. Emerg Infect Dis 2009; 15: 1236-1242.

3. Moon EK, Park HR, Quan FS, Kong HH. Efficacy of Korean multipurpose contact lens disinfecting solutions against Acanthamoeba castellanii. Korean J Parasitol 2016; 54: 697-702.
4. Turner NA, Russell AD, Furr JR, Lloyd D. Acanthamoeba spp., antimicrobial agents and contact lenses. Sci Prog 1999; 82: 1-8.

5. Jha BK, Jung HJ, Seo I, Kim HA, Suh SI, Suh MH, Baek WK. Chloroquine has a cytotoxic effect on Acanthamoeba encystation through modulation of autophagy. Antimicrob Agents Chemother 2014; 58: 6235-6241.

6. Moon EK, Kim SH, Hong Y, Chung DI, Goo YK, Kong HH. Autophagy inhibitors as a potential antiamoebic treatment for Acanthamoeba keratitis. Antimicrob Agents Chemother 2015; 59 : 4020-4025.

7. Moon EK, Hong Y, Chung DI, Goo YK, Kong HH. Potential value of cellulose synthesis inhibitors combined with PHMB in the treatment of Acanthamoeba keratitis. Cornea 2015; 34: 15931598.

8. Ortillés Á, Belloc J, Rubio E, Fernández MT, Benito M, Cristóbal JÁ, Calvo B, Goñi P. In-vitro development of an effective treatment for Acanthamoeba keratitis. Int J Antimicrob Agents 2017; 50: 325-333

9. Tomlinson G, Jones EA. Isolation of cellulose from the cyst wall of a soil amoeba. Biochim Biophys Acta 1962; 63: 194-200.

10. Dudley R, Alsam S, Khan NA. Cellulose biosynthesis pathway is a potential target in the improved treatment of Acanthamoeba keratitis. Appl Microbiol Biotechnol 2007; 75: 133-140.

11. Bowers B, Korn ED. The fine structure of Acanthamoeba castellanii (Neff strain). II. Encystment. J Cell Biol 1969; 41: 786-805.

12. Beattie TK, Seal DV, Tomlinson A, McFadyen AK, Grimason AM. Determination of amoebicidal activities of multipurpose contact lens solutions by using a most probable number enumeration technique. J Clin Microbiol 2003; 41: 2992-3000.

13. Moon EK, Chung DI, Hong YC, Kong HH. Autophagy protein 8 mediating autophagosome in encysting Acanthamoeba. Mol Biochem Parasitol 2009; 168: 43-48. 

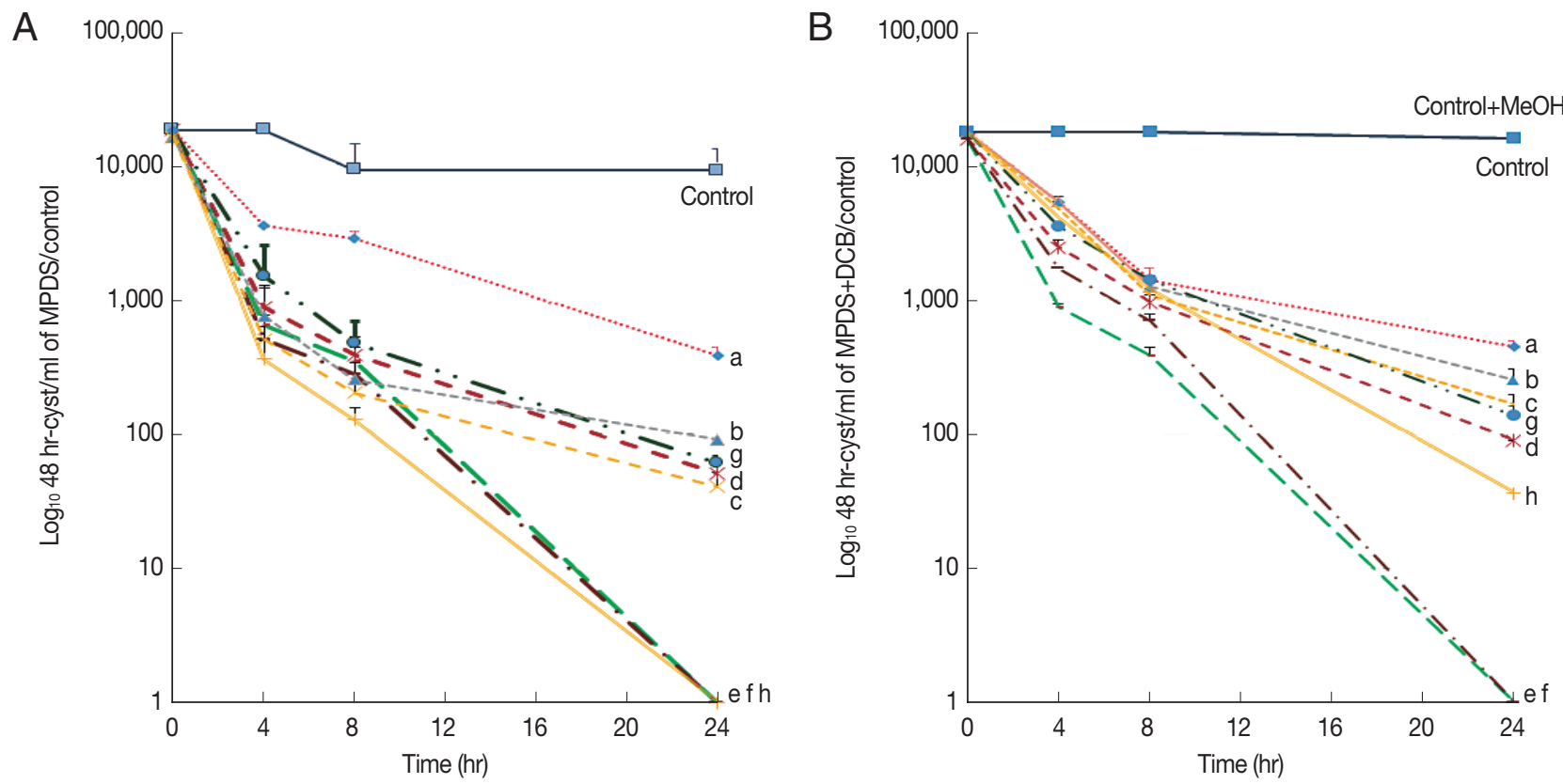

Supplementary Fig. S1. A most probable number of Acanthamoeba 48 hr-induced cysts after incubation with 8 commercial MPDS (solution a-h) and the combination of MPDS with $100 \mu \mathrm{M} \mathrm{DCB}$. (A) showed amoebicidal activity of MPDS to 48 hr-induced cysts, and (B) showed that of MPDS combined with $100 \mu \mathrm{M}$ DCB. Data are presented as mean \pm SEM from three independent experiments. 